\title{
The Factors Affecting the Location of Medical Centers in Tehran City Case Study: District 1 of Tehran Municipality
}

Factores que afectan la ubicación de los centros médicos en la ciudad de Teherán Estudio de caso: Distrito 1 del municipio de Teherán

Author:

Morteza Najafi,**

Danial Edalat khah ${ }^{2}$

Mohammad Reza Asadi Yeganeh ${ }^{3}$

SCIENTIFIC RESEARCH

How to cite this paper:

Najafi. M., Khah. D. E., Asadi-Yeganeh. M. R. The Factors Affecting the Location of Medical Centers in Tehran City Case Study: District 1 of Teherán Municipality. Tehran, Iran. Innovaciencia. 2019; 7 (2): 1-15. DOI: http://dx.doi.org/10.15649/2346075X.767

Reception date:

Received: 16 March 2019

Accepted: 2 May 2019

Published: 25 October 2019

Keywords:

Medical centers, geographical information system (GIS), location, District 1 of Tehran Municipality

\section{ABSTRACT}

The historical growth of cities due to the rapid increase of population led to the increased land price in cities and caused problems to the appropriate distribution system as well as the allocation of suitable spaces to some fundamental services like medical centers. Supplying health for all people in every society is one of the basic human rights which should be regarded by governments. The imbalance in fundamental services such as medical care and its imbalanced distribution system cause major challenges expressing themselves in different economic and skeletal dimensions. In this study which aimed at determining the factors affecting the location of medical centers, first the main variables and indicators affecting the location of such centers were extracted and then ranked using the hierarchical questionnaire by some relevant experts. After ranking the obtained indicators using the hierarchical method to examine the medical centers at district 1 of Tehran and investigating the balance and proportion of medical centers, the location of medical centers in district 1 were examined using the geographical information system by hierarchical model. The obtained results indicated that the northeast and east areas of district 1 in Tehran had faced major challenges in terms of the access to medical centers and a specified area in the geographical information system indicated this challenge in the north and northeast areas. The selected point by geographical information system were the areas in this district.

Corresponding author: Morteza Najafi

1 Postgraduate student, urban planning, faculty of art, Tarbiat Modares University, Tehran. Email: mortezanajafi.m.n@outlook.com

2 Postgraduate student, urban planning, Islamic Azad University, Pardis branch, Tehran

3 Postgraduate student, regional planning, Islamic Azad University, Central Tehran branch 


\section{INTRODUCTION}

The global organizations like the world health organization consider the health right as the most significant social goal of a society and enjoying the health as the basis of sustainable development and one of the major bases for achieving social justice. Facilitating the access of people to medical health services is one of the major goals of policy makers in the health sector, so that all people in a society can take advantage of such services in the best way. Meanwhile, hospitals and medical centers are one of the most significant institutions which can affect the health of society in the current era. Modern hospitals are significant because they use a large part of resources and take advantage of the supplying, maintaining, and promoting the health of people in the society. Equal access to health services like hospital services is one of the fundamental human rights. In this regard, inequality in the spatial distribution of health sector resources made the equal access of people to health medical services difficult.

Resources are often allocated unequally in developing countries due to the lack of information, skill, and expertise in the field of health medical planning. In this regard, the settlement location of public medical centers can be considered as one of the indicators of access to health cares. Since creating new services requires huge costs, thus determining the best location for these centers, in such a way that more citizens take advantage of such services, is of great significance. The lack of selecting an optimal location for creating hospitals will create some problems which were gained in big cities since the last years indicating that the location of a hospital should be near green spaces, parks, and far from crowded areas, the access to the hospitals should be easy or in other words they should be located near the main roads, they should be close to the centers with high population density, so that more citizens can take advantage of the services, and finally they should be at an appropriate distance from hospital centers to distribute the medical services in the city appropriately ${ }^{[1]}$.

In recent years, urbanization has become a nonavoidable global process. Urban population formed
$14 \%$ of the world population in 1920 while it reached $29 \%$ in 1950 and $37 \%$ in 1975 . More than $50 \%$ of the world populations are currently living in urban areas ${ }^{[2]}$.

Thus, urbanization is a developing dynamic process and is considered as a dominant phenomenon in all developi8ng countries ${ }^{[3]}$. In Iran, the cities faced an unprecedented growth after the land reforms and the severe increase of rural-urban migrations. Mediumsized cities were not an exception. The increase of population was associated with the skeletal growth of cities. With the severe migrations of rural population to cities, the rapid growth of urban population, the unprecedented skeletal growth of cities, joining of surrounding villages to cities, sprawl phenomenon, and the lack of financial -technical ability in providing services in recent decades caused some problems in cities such as the distribution of urban services especially medical services. The balanced distribution of uses is one of the skeletal-spatial goals of urban land use planning ${ }^{[4]}$.

On the other hand, the equal access to public medical services for different classes of society or the balanced distribution of these services are the significant principles of social welfare ${ }^{[5]}$. Geographic information system is quantitative technique in decision-making, determining the processes, and location which are used in the studies related to the different place and levels of planning. Todays, using the geographical system is one of the most efficient methods for promoting policy-making and improving the urban plans. Thus, having an advanced and complete geographical information system is one of the most efficient methods for promoting policy making and improving the urban plans. Thus, having an advanced and complete geographical information system provides the best context for different kinds of planning and increases efficiency in implementing the plans even in different sectors of urban services ${ }^{[6]}$.

Tehran, as the capital of Tehran province, has faced the over increase of population and unplanned physical growth in some urban areas due to some factors like rural-urban migration, increasing the growth of population, etc. However, no appropriate space was considered in terms of optimal-spatial 
distribution and fair location for public services uses especially the health medical services to which the easy, timely, and quick access is of great significance ${ }^{[7]}$. District 1 of Tehran is considered as one of the significant areas of Tehran due to its specific geography which faced main challenges in terms of spatial justice and distribution of services and facilities. This study aimed to find the factors affecting the location of medical centers in district 1 of Tehran municipality.

Thus, the objectives of this study on the factors affecting the location of medical centers in district 1 of Tehran and ranking them based on the current conditions using the raised variables of appropriate zones were specified for creating medical centers in district 1.

The idea of the location of hospitals was raised by Leslie Mihio in Birkbeck, London whose main task was developing a spatial model for the pre-referral of patients to hospitals which was resulted from the changes in the supply and demand of non-hospital services ${ }^{[8]}$. The studies on medical centers and its location being conducted in recent years are as follows:

Zu and Woo (2012) in a study in Beijing dealt with the optimal location for establishing hospitals. In this study, the AHP was used as one of the multi criteria analysis methods and GIS. The results of the study indicated that using the analytic hierarchy process in hospital location was highly efficient in the studied area.

Hatami Nejad et al (2012) studied the location of health medical centers using the GIS in four districts of Shiraz. In this study, the lands in district 4 were classified into four groups of excellent, good, average, and weak. The results indicated that the appropriate lands for establishing hospitals were located near the residential areas, green spaces, and communication roads.

Eshghali et al (2012) evaluated the hospital location models in Tabriz. In this study, the AHP model and overlapping index were used due to 13 complicated and incompatible criteria. The obtained results indicated that the number of hospitals and beds in some areas were not enough.
Tahari Mehrjuyi et al (2011) in a study used the multi criteria decision making techniques in Yazd city to identify and prioritize the factors affecting the improvement of quality of health medical services. They concluded that the managers of health medical services can prioritize and plan using the multi criteria decision making techniques to strengthen and modify the chaos.

\section{RESEARCH METHOD}

Scientific research process refers to a set of regular and continuous steps enabling the scientific research from the beginning to the end. Scientific research process includes the general steps in which a subprocess including more detailed steps as well as appropriate operations are conducted ${ }^{[9]}$.

Obviously, the research method aimed at answering the objectives and questions on the variables affecting the location and appropriate areas for the location of medical centers. In other words, research methods are a tool by which the researcher realizes the research objectives and proves the questions and hypotheses. If we look at the paradigm of the current method, we can find three components of ontology which were the subject of centers location along the epistemology which includes the qualitative and quantitative method with the methodology using the spatial and qualitative analyses to achieve the objective and answer the questions.

The present study was applied in terms of objective and explanatory, descriptive, and analytical in terms of method. In addition, it was documentary-library and field in terms of data collection method using GIS and Global mappar software. First, the variables were identified using the articles, documents, and field study. After extracting the variables, a questionnaire was prepared hierarchically and then completed by seven relevant experts. The variables were weighed after the analysis and extraction of variables. After weighing each variable, the database of variables was formed using GIS software. After creating the spatial data using the ADP location method, the appropriate areas for creating medical centers were specified. Global mapper software was used to build the database. In addition, Expert Choice software was used to rank and weigh the variables. 


\section{THEORETICAL FOUNDATIONS}

The spatial analysis of proportionality in a process determining the appropriate place in a specified area for a specific use ${ }^{[10]}$. The objectives of land analysis of proportionality are expressed in the concepts like spatial analysis of proportionality and indicate the significance of uses in urban space and the significance of its placement in urban space.

\section{The standards of medical location}

In general, standard means a level of implementation which is determined by certain criteria. In other words, the factors like weather (in determining the population density, urban texture, number of building floors, and city size), price, social factors, and economic factors are involved to determine the minimum required land for each criterion. There are usually standard and sizes for different cities in the world which are different from each other in most aspects ${ }^{[12]}$. The method of determining per capita is specified by the facilities and level of urban development as well as its economic-social conditions and population needs. Thus, the criteria should be determined for each use (like residential, recreational, medical, and educational uses) and the relevant components $\stackrel{[13]}{ }$.
Five main principles should be considered for determining the best medical centers:

Access: The important criterion in the location of these centers is the easy access.

Distance: Evaluating the distance in the location of centers is based on the influence and population threshold.

Proximity (Compatibility): The presence of some inappropriate uses like industrial and pollutant centers next to medical centers reduces the efficiency of these centers in terms of keeping the patients calm and relaxed.

Service radius: The covering radius of the performance of each medical center to other medical centers.

Population: This indicator is of great significance in relation to the establishment or expansion or medical centers.

The capacity of these centers is a function of the number of population and distribution of population in the city ${ }^{[14]}$.

Table 1. The location criteria of urban medical centers

\begin{tabular}{ll}
\hline Features based on general criteria & Title \\
\hline $\begin{array}{l}\text { At least } 10000 \text { households } \\
\text { Maximum of } 14000 \text { households }\end{array}$ & Service provider direction \\
$\begin{array}{l}\text { Population under coverage } 10000 \text { households, with average capacity of } \\
300 \text { beds }\end{array}$ & Access radius \\
\hline Distance to residential neighborhoods $1-1.5 \mathrm{~km}$ & The required per capita and space \\
\hline $\begin{array}{l}\text { The required area for each bed at least } 50 \text { square meters for } 1000 \text { patients } \\
370 \text { square meters and } 1.73 \text { hospital beds are needed. }\end{array}$ & Type of communications \\
\hline It should be located on main roads. & Design criteria \\
\hline $\begin{array}{l}\text { Maximum distance to residential neighborhoods } 2 \mathrm{~km} \\
\text { Minimum distance to annoying industrial workshops } 1 \mathrm{~km} \\
\text { It should be built on flat lands and should be far from noisy } \\
\text { neighborhoods }\end{array}$ & \\
\hline $\begin{array}{l}\text { Proximity to other uses of the area of the district c enter } \\
\text { Proximity to the green space of the region }\end{array}$ & Priority of compatibility \\
\hline
\end{tabular}

Source: Razavi, urban planning, land use, 2002 
The location of medical uses should be conducted based on the need and rapid access of people. In addition, it should be away from noise, population density, and traffic and should also have the wide green space for freshening the environment air. Medical uses have some standards due to their specific features but these standards are in relation to different cities and the type of health medical units. In some countries, the required area for hospital is 100 to 200 square meters versus each hospital bed and in some other countries, one hospital is considered for 45000 to 50000 residents in the city. In addition, sometimes nine to ten hospital beds are predicted versus 1000 citizens.

For clinics, 1 to 2 square meters are required versus the urban residents. These ratios are one pharmacy for 7000 people and one dentistry office for 2000 people.

Health uses are dealt with public health in the city and are of great necessary. The location of such uses should be in such a way that the access to them is easy for everyone, although the number of these closed centers depends on the population rate and their lifestyle ${ }^{[15]}$. Four basic criteria are raised in evaluating and locating the medical centers.

1. Compatibility

2. Utility

3. Capacity

4. Dependency

\section{Compatibility}

Compatibility means the placement of compatible uses next to each other and the separation of incompatible uses from each other ${ }^{[16]}$.

- Avoiding environmental pollutions

- Noise pollution

Noise pollution is one of the phenomena due to the development of cities. Such a factor does not kill humans and animals directly but weakens the auditory system, causes full deafness, stress, blood pressure, and endangers human health ${ }^{[17]}$.
Urban uses and activities mentioned by Rahnama in 2004 are not basically similar in terms of noise comfort and cannot be dealt with equally. Based on the global experiences, urban uses are usually classified in three groups in terms of noise comfort thresholds:

A. The educational uses sensitive to noise pollution (like residential, educational, and health)

B. The semi-sensitive uses to noise pollution (offices and cultural centers)

C. The non-sensitive uses to noise pollution (airports, terminals, industrial units, etc.)

The compatible uses with medical uses

Cultural uses

Religious uses

Green space

Residential

Communication roads

Transportation network and terminal use

Compatible uses with medical uses

Garbage collection site

Workshops and annoying industries

Gas station and other fuel storage places

Slaughterhouses, animal husbandry, and aviculture

High pressure electricity pylons

\section{- Utility}

Utility in the planning of urban land use means the effort in keeping and maintaining the natural factors, creating open and pleasant spaces, forming the roads, buildings, and urban space ${ }^{[4]}$.

In the utility of road network, directions should be located in such a way that pedestrians and drivers have the maximum pleasure from the urban landscapes ${ }^{[17]}$.

In the utility function, the compatibility between use and its settlement is evaluated. Accordingly, it can be said that each use is appropriate for a specific place according to its particular features and each place has its own specific use. By comparing the factors and 
features of the settlement location of each use, it can be concluded that the settlement place of each use is completely favorable, relatively favorable, relatively unfavorable, or completely unfavorable. Accordingly, the appropriate decision can be made in the spatial distribution of uses in the city ${ }^{[4]}$.

- Environmental conditions

- Topography and geology

- Land form and slope

- Soil quality

- Natural disasters ${ }^{[18]}$

- Access radius

- The distance passed for accessing the medical environment

- Access network including the main roads

- Capacity

Every urban activity (use) has a scale. As the structure of a city has different levels of skeleton and as the two above-mentioned scales match to each other, every use will have an appropriate performance and each level of urban structure will effectively take advantage of activity service and if it is not matched, many problems will be created for the two phenomena ${ }^{[4]}$.

Medical space per capita

Density

Covered population

\section{- Dependency}

Sometimes the activity of a use depends on the activity or other activities of uses. For example, a residential neighborhood is incomplete without the presence of educational, medical, and commercial services and other urban centers are somehow related to other urban activities ${ }^{[4]}$. Meanwhile, the first three metrics examined the incompatibility of each use with other uses, settlement location, and the capacity of urban structure and attempted to specify the incompatible, unfavorable, inappropriate, and independent, its location should be certainly changed ${ }^{[19]}$. The history of location for medical centers such as hospitals reaches to less than half a century. The UK Department of Health and
Social Welfare in 1979 paid a special attention to the strategic development of health medical service centers in cities and then the studies on this subject began and followed in Austria in 1980 and 1982. The idea of location for hospital centers was later raised by Leslie Mihio in his doctoral dissertation based on the above-mentioned studies.

These studies were conducted in the department of geography in Birkbeck College, London and the main task of the author was developing a spatial model for predicting the referral of patients to the hospital.

\section{Location}

Location is a process for evaluating a physical environment which provides the conditions and supports human activities. The main purpose of location assessment for having a specific land use is to ensure that the development and expansion of human activities have compatibility and coordination due to the facilities and limitations ${ }^{[20]}$. In the issue of location, service providers aim to find how and where they should establish their centers to have the required efficiency in covering and answering the future demands. Population and need increase require these centers and forces be settled where they cover the needs of citizens, show the appropriate reaction as soon as possible, and provide the satisfaction of its stakeholders. Such investigations have been recently made for active centers and some reviews were made in their settlement ${ }^{[21]}$.

\section{Analytic hierarchy process in GIS}

Today's world is the world of information and its optimal management. A major part of decisions made by managers and planners in different construction, environmental, defense, security, and service projects is related to a specific place and situation. Thus, the presence of accurate, reliable, and timely geographical information as well as its optimal management is one of the very fundamental issues in the situation of these decisions and their implementation. In this regard, the huge amount of available data, different mechanisms in receiving, storing, recovering, updating, processing, displaying, 
using, and exchanging the data of the reference location, the lack of standard and comprehensive instructions in this regard, the presence of different storage and processing environments, the presence of a lot of information as analogue, separate spatial and descriptive information in most cases, and the absence of a systematic thought in management, access, and use of information made the optimal management to face many problems. The significance of using GIS in urban planning was revealed with the very fast expansion of cities and significant increase of information size which should be processed for urban management ${ }^{[22]}$.

\section{Weighing methods and combining layers in GIS}

The common problems of multi criteria decision making (MCDM) are the different significance of criteria and sub criteria for decision makers that the information on the relative significance of all criteria and sub criteria to each other is required. Extracting and determining weights is a significant step in the extraction of decision making criteria.

\section{- Ranking and reverse ranking methods}

The simplest method for evaluating the weight of criteria is sorting and ranking them based on the significance and priority of decision makers. Ranking is possible in two ways including ascending ranking (top significance $=0$, second significance $=2$, etc.) and reverse ranking (the least significance $=0$, the next least significance $=2$, etc.). after ranking the criteria, there are several methods for creating numerical weights using the above-mentioned information the most common of which include the total rank, reverse rank, and rank exponentiation.

$$
W_{J}=\frac{n-r_{j}+1}{\sum(n-r j+1)}
$$

Wj represents the normalized weight for $\mathrm{n}, \mathrm{j}$ criterion under the studied criteria $k=1,2,3, \ldots, n$ and $\mathrm{rj}$ represents the status of standard rank. Ranking methods are considered due to high simplicity. Although its usefulness is limited to the number of ranked criteria, using this method is more inappropriate for increasing the number of criteria.
This method is also criticized due to the lack of a strong theory. It was experimentally shown that the above-mentioned method can be used as weight approximation techniques. Studies indicated that ranking methods create satisfactory results for evaluating the weights in most decision making situations. It was also suggested that ranking methods are only used on simple multi criteria analyses and using this method is not recommended in weighing the multi criteria decision making.

\section{- Pairwise comparison method}

Pairwise comparison method was presented by Saaty in 1997 in the field of AHP. In this method, the pairwise comparison of criteria is used and relative weights are created as the output. Pairwise comparison method includes three main steps: creating the hierarchical structure, calculating the weights, and system compatibility.

This comparison method has time-consuming calculations that computer programs can conduct the required calculations. The most common specialized software for this method is Expert choice. In addition, this method can be conducted simply in the spreadsheet. Another point on the pairwise comparison is that it was combined with GIS decision making methods and was conducted for the first time in GIS by Rao et al in 1991 [23].

\section{Analytic hierarchy process (AHP)}

AHP method that was presented by Thomas Saaty is based on the following three principles:

1. Decomposition: In fact, the complicated structure of a problem in different categories and hierarchies is simplified.

2. Pairwise comparison: Creating a pairwise comparison for all studied elements or criteria for extracting the weight and prioritizing the variables.

3. Combining the hierarchy: Using the local comparisons of hierarchies to achieve the real value of weights. 


\section{The conditions of AHP}

The conditions of AHP include the following four main factors ${ }^{[24]}$ :

1. Reverse condition: If the preference of element $A$ to element $B$ equals $n$, the preference of element B to element $A$ will equal 1/n.

2. Homogeneity: Element A with element B should be homogenous and comparable. In other words, the preference of element A to element B cannot be infinite or zero.

3. Dependency: Each hierarchical element can depend on the element of higher level and this dependency can continue hierarchy to the highest level.

4. Expectations: when any change occurs in the hierarchical structure, the evaluation process should be re-conducted.

\section{MATERIALS AND METHODS}

Studying and identifying the studied area General and mathematical status of district 1 of Tehran

District 1 of Tehran with an area of 36048944 hectares is considered as the northeast region, so that its north border is compatible with the north border of Tehran (height lines $1800 \mathrm{~m}$ ). This area of the west is limited to district 2 bon the west by Darakeh River, to district 3 on the south by Chamran, Modarres, and Sadr highways, and to district 4 on the southeast by Ozgol highway.

The population of this district was estimated to be about 270000 people based on the initial results of general-workshop census in October 2002. This district has less building and population density than the other districts in Tehran, so that the average building density in 10825 square meters per hectare and the average net residential density is 182.5 people per hectare while not all neighborhoods of the district are in the same conditions.

Map 1. Research area

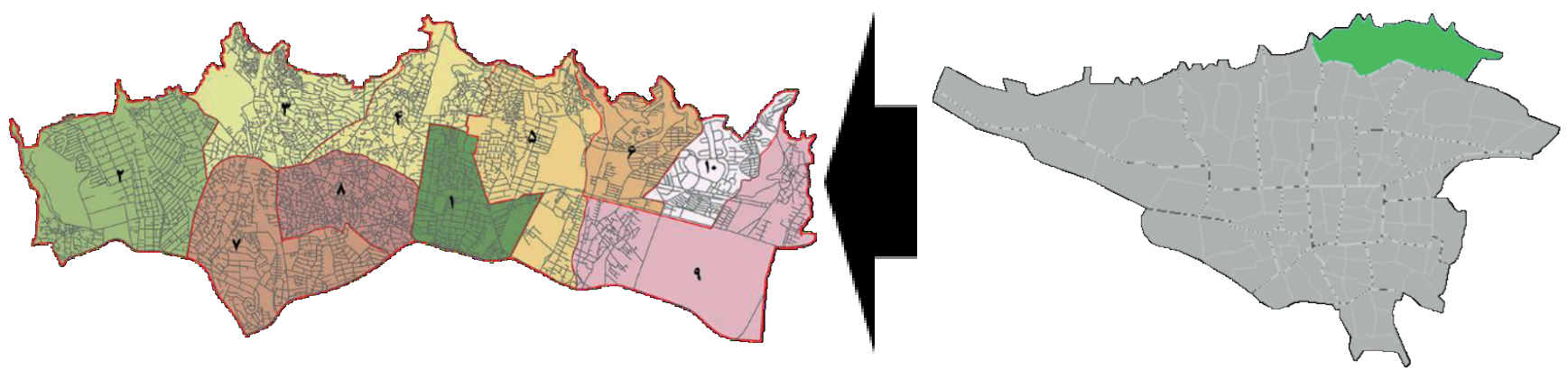

Identifying the significance and prominent uses in the region

Based on the residential history of district 1, the residential use with allocating 1571 hectares, i.e. $43.58 \%$ of the area includes the maximum level of the area in district 1 indicating the dominance of residential use in the district (of the total residential area, 63.0957 hectares include the residential complexes).

One of features of district 1 is the presence of wide wasteland in the district that is at the third rank of uses with an area of 442 hectares, i.e. $12.27 \%$ and includes a large part of the north of the district.
However, there are some wastelands among the constructed texture in the district which are gradually being constructed. The considerable point on wastelands is the presence of most of these lands in inappropriate slopes for construction which are used for building construction despite this constraint.

A major part of this use is allocated to the district parking lots and the warehouses include a small percent of this area. Religious use allocates seven hectares of the district and is the $20^{\text {th }}$ use of the district in terms of area. In the next ranks, there are 
social services, industry, and health uses allocating the ranks 21, 22, and 23 in ranking the uses.

The interesting point is the low area of industries in district 1 which is considered as positive feature in this regard.

The location of medical centers in district 1 of Tehran was due to two general issues in the major problems of district 1, Tehran. The concept of urban justice was a direct relationship in use division in line with the easy and appropriate access of citizens in the district to the above-mentioned use. The significance of this issue can be observed in the attitudes of Aristotle utopia focusing on the easy and quick access of citizens to the required use. Medical uses are among the significant uses in urban space and the access to these uses has a great significance. Thus, the location of these centers has a high social significance. However, it should be noted that this use can create some problems such as health and traffic problems. District 1 of Tehran has an area of about 64 square kilometers. The population of this district was 439.467 in 2011 . The mass of ready and semiconstructed buildings in a near future will increase the population of the district to 500000 people. The interesting point is firstly the low per capita of medical centers and secondly the appropriate access to medical centers. the per capita of medical centers was 1.74 and the total share of the district was $1.30 \%$ while the area of the medical centers was 64.8830 hectares.

As indicated in the following map, some areas of district 1 have an appropriate per capita and easier access to medical centers. On the contrary, the access is low in some areas and consequently its per capita is low too.

Map 2. The location of medical centers and access to medical centers in district 1 of Tehran
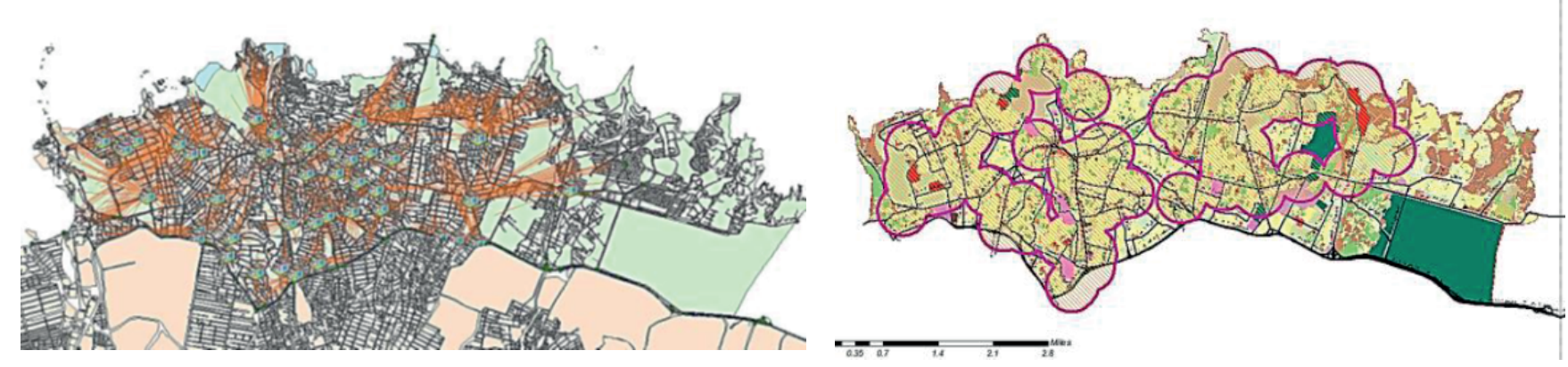

As shown in the above table, the eastern areas of district 1 have low per capita and one of the limited access types to medical centers using the network analyst extension.

The materials extracted from theoretical studies:

Studying the medical centers based on four factors of proximity (compatibility and incompatibility), utility, capacity, and dependency

\section{Proximity}

In this section, the distribution of medical centers (hospital, clinic) in relation to the surrounding uses is studied in terms of proximity type regarding the compatibility and incompatibility with these uses.

\section{Compatible use}

Compatible uses include gas station, workshop, cemetery, and slaughterhouse.

\section{Gas station}

The incompatibility of gas station for medical centers is as follows in terms of two general perspectives: the probability of occurring an accident and its penetration to medical areas which are even considered as the essential factors of accidents after the passive defense. however, the second perspectives emanate from noise pollution on gas station. Thus, it was among the issues allocating a low level in location. 


\section{Compatible use}

Green space is one of the compatible uses with medical centers. this use includes parks, gardens, public green spaces, etc. which have been highly effective in cleaning the air and creating flexibility. Most emphasis in all studies about medical spaces indicate the relationship and closeness of these spaces to green space.

The proposed land should not be close to the following uses and the minimum distance should be observed: (the design criteria of medical centers and hospitals, ministry of health, the ministry of health and medical education, the department of resources development and management)

Industrial workshops (at least $200 \mathrm{~m}$ )

Military barracks (except military medical centers, at least $1000 \mathrm{~m})$

Airport (at least $2000 \mathrm{~m}$ from runway)

Railway, bus, and truck station (at least $500 \mathrm{~m}$ )

Police stations (at least $200 \mathrm{~m}$ )
Communications, radios, and TV stations (at least $100 \mathrm{~m}$ )

Stadiums (at least $200 \mathrm{~m}$ )

The main and entrance side of hospitals next to residential texture

Other annoying uses recognized by the experts visiting the site

- The proposed land should not be located on the drainage divide, thalweg, or next to fault.

- The proposed land should not be located next to river or on the way of mountain and avalanche

- In the proposed land, there should be no natural barriers such as high pressure electricity pylons, gas and oil pipes, etc. In addition, the water and wastewater channels should not pass from inside the proposed land and the announced privacies should be observed.

- Observing the requirements of passive defense in all capital property ownership plans according to paragraph A, Article 215 of the fifth plan law.

Table 2. The criteria affecting the location of hospital

Closeness to medical centers

The living place of human is the most important part of the city and allocates a major share of use levels, so that more than $60 \%$ in small cities and about $40 \%$ in big cities are covered by residential use.

Green space is one of the proximities appropriate to the hospital centers. Human has a tendency to nature and creating a relationship with it. Green space affects human soul and reduces atmospheric pollutions. Green space in a broader scale reduces noise pollution. For this reason, less score was given to the more distance from medical centers to green spaces and as the distance from these spaces is less, more scores are given.

\section{Criterion}

Closeness to populated neighborhoods and centers

Closeness to urban green space

One of the basic criteria for locating hospitals, access to top main roads to take the

Closeness to main roads patients to these hospitals on time. For this reason, in this study less score is given as the distance of medical centers to the main roads is more and higher score is given as the distance from these spaces is less.

In medical services uses such as hospital, the closen ess to fire stations is of great

Closeness to fire stations significance due to the large number of patients and hospital personnel. Accordingly, medical centers gain more scores as they are closer to fire stations.

As one of the main goals of land use planning is the comfort of all citizens, thus the facilities such as medical centers in the city should be distributed equally to achieve this goal. Accordingly, the lands having more distance from the current medical centers have more values and vice versa

Land slope is one of the natural criteria in urban construction. The maximum appropriate slope for urbanism is usually $9 \%$. The slope with high percent increases Distance from slope urbanism costs and the slopes close to zero are problematic in terms of wastewater drainage. 
Industry is one of the incompatible uses with medical centers and causes the

Distance from industrial centers problems such as environmental pollution and noise. Thus, observing the distance from them is one of the initial principles of location for medical centers. For this reason, as the medical centers are far from the industries, their value will be added and as they are close to the industries, their value will be reduced.

In creating cemetery, their situation in relation to the development of city future should be considered. Cemeteries should be constructed in such a way not to be exposed to the main wind blow to the city. In addition, the burial of the dead in old cemeter ies (especially those which are inside the city) should be prevented. In addition, the location of collective facilities like hospitals should not be close to cemetery. Accordingly, as hospitals are far from cemeteries, they will have more values and viceversa.

These lands are only raised at the city scale and are beyond the garrisons, headquarters, shooting ranges, motive power depots, military airports, and staff offices. In the comprehensive plan, only the settlement of staff units is allowed and the High Council for Urbanism and Architecture of Iran demanded the evacuation of all military lands which are mainly as educational and military garrisons through a circular.

The closeness to medical centers and hospitals in conflict with sport centers due to its intrinsic nature, i.e. emotion, activities, and noise. Thus, as hospitals are far from sport centers, their value will be added and vice versa.

Distance from cemetery

Distance from military centers

The closeness of medical centers and hospitals to educational centers especially in low educational levels has high negative effect on spirit weakening and negative psychological effects. In addition, the pollution rate and disease transmission are of great signifi-

Distance from educational centers cance in terms of traffic volume. The location of hospitals should be selected by observing the privacy to educational centers. Thus, as hospitals are far from educational, their value will be added and vice versa.

\section{Utility}

In terms of utility, the distribution of medical centers was evaluated in relation to the factors such as access (transit network), environmental conditions, and access radius.

Access: The ease of access is the important criteria in the location of these centers.

Distance: Evaluating distance in the location of centers is based on the penetration area and population threshold.

\section{Environmental conditions}

Environmental conditions indicate the natural, climatic, geological, and topographic status of the studied area. Settling the medical centers is the function of its specific functions and performances.
The criteria on land slope, fault, flood, the relevant privacy, and the third wind blow direction.

\section{Dependency and capacity}

Based on the above-mentioned rules and regulations of the medical centers, the medical centers had the uses such as green space from the rules and standards on dependency while it should not be noted that such a dependency was not essential. In case of capacity, table 2 indicated the capacity in general.

\section{THE ANALYSIS OF LOCATION CRITERIA FOR MEDICAL CENTERS}

At this section, the criteria which are effective as the criteria affecting the location of medical centers are weighed as pairwise. Such a weighing was conducted using seven relevant experts and completing the hierarchical questionnaire and then analyzed by Expert choice software. 
Table 3. The valuation rate of criteria

\begin{tabular}{lllllll}
\hline Equal preference & Intermediate (so -so) & Slightly preferred & Intermediate (so -so) & Better & Very good & Excellent \\
\hline 1 & 2 & 3 & $2,4,6,8$ & 5 & 7 & 9 \\
\hline
\end{tabular}

Table 4. Weighing the variables using AHP by the relevant experts in district 1 of Tehran

\begin{tabular}{ll}
\hline Criterion weight & Criterion name \\
\hline 9.05 & Distance from cemetery and industrial areas \\
5.15 & Hazardous areas such as fault \\
6.69 & Population density and proximity to neighborhood centers \\
16.51 & Urban use (the distance and proximity of uses such as educational, etc.) \\
4.60 & Land slope \\
30.69 & Penetrability and access (proximity to main roads) \\
13.81 & Proximity to medical centers \\
3.62 & Slope direction \\
9.88 & Closeness to green space \\
\hline
\end{tabular}

Then, the appropriate area for medical centers is determined after weighing and specifying the significance of each variable using GIS software.

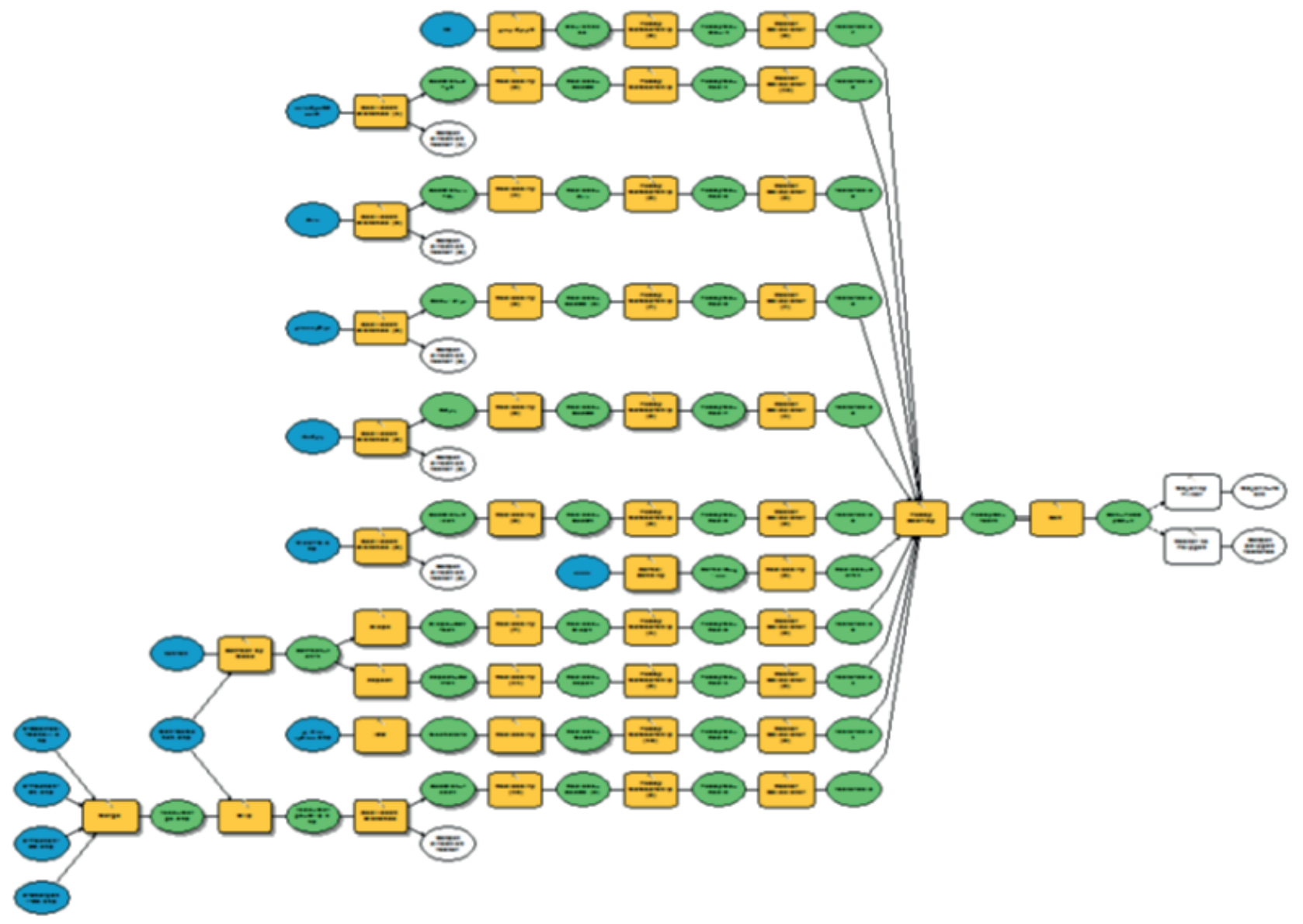



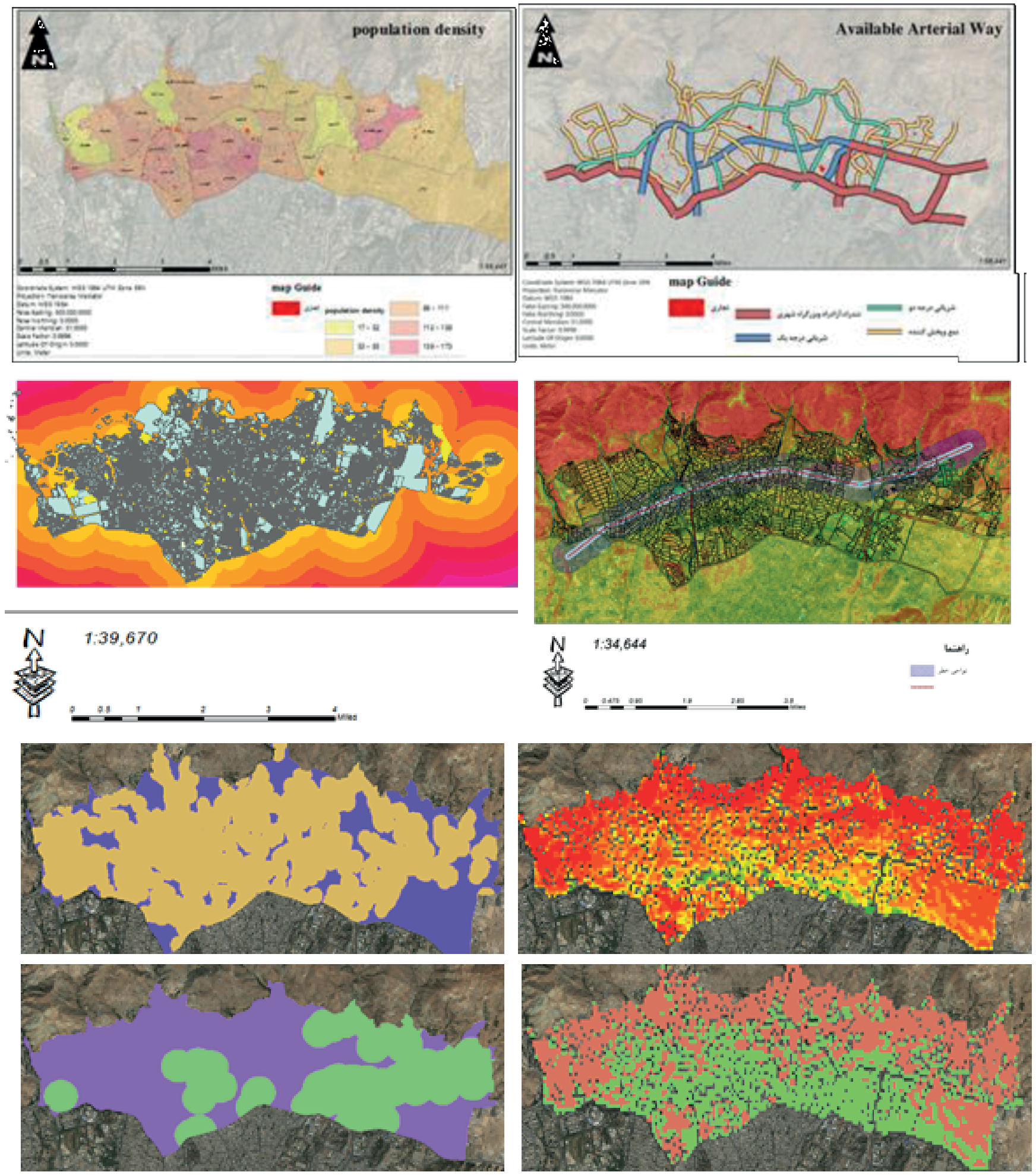

Figure 1. The general structure and executive model in GIS software

At this section, the slope rate which was an effective factor in location was obtained using the height layer. Then, the slope and closeness to fault was prepared using the current tools. As map 1 indicates, the slope rate in the northern areas was higher. The areas shown by red had higher slope than green areas. The proposed land should not be located in drainage divide, thalweg, or adjacent to fault. Other location maps were completed like this. Figure 1 shows the determined map. 


\section{CONCLUSION} The process continued for the other nine maps. on each other.
Then, the appropriate areas for creating medical centers were selected by putting the obtained layers

Map 4. Putting the layers on each other

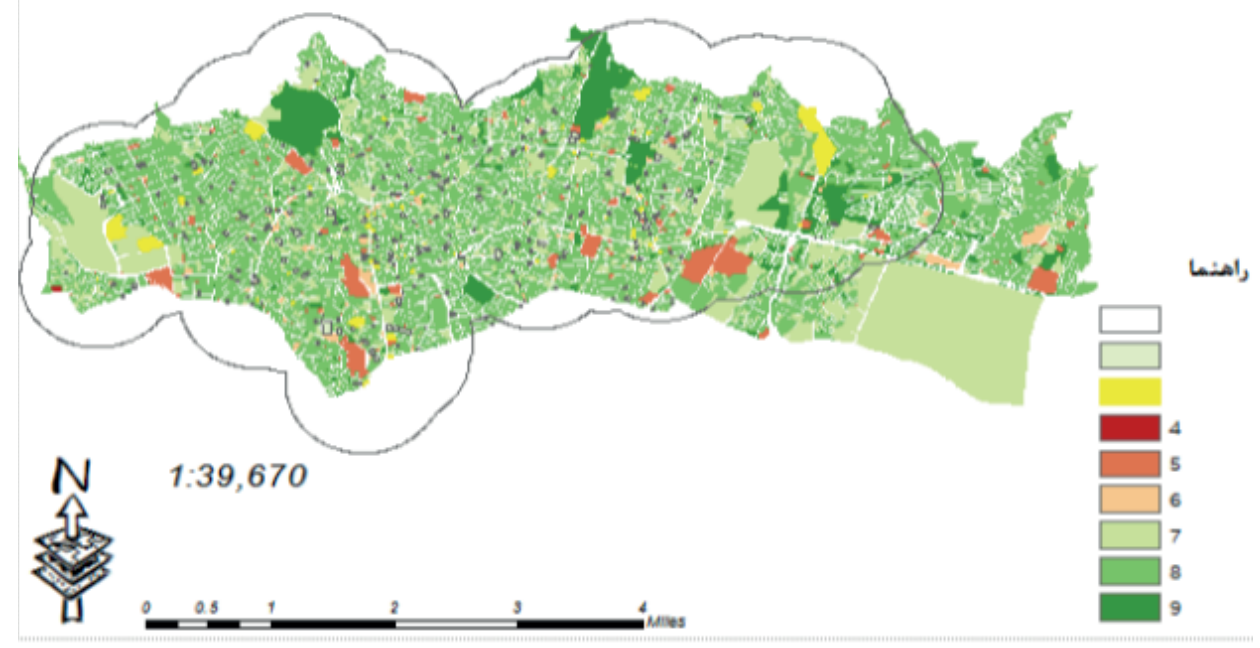

As map 4 shows, the areas with value 9 are the favorable areas for creating medical spaces. However, it should be noted that the areas which are within the problem range of the access radius of current hospitals was because the space for creating a medical space was considered. The significant point is Mahak hospital with a high access distance due to the bad location and access.

Map 5. Appropriate regions for creating a medical center

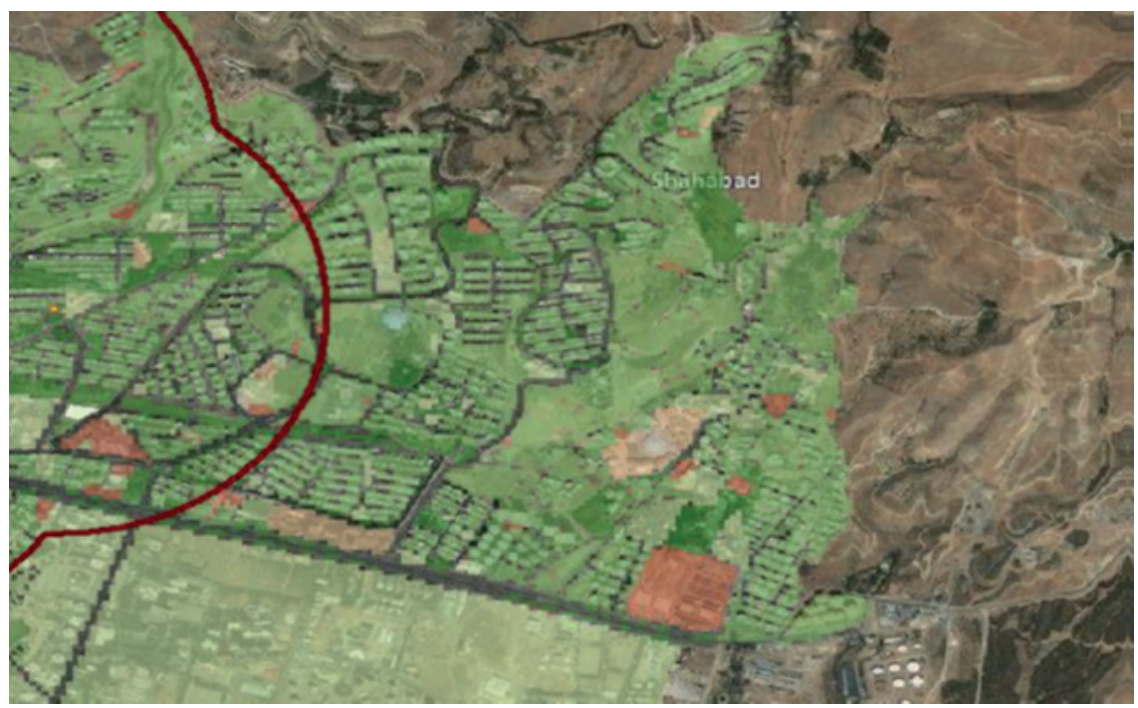

Finally, the specified points indicated that medical centers can be placed in line with the fair distribution of services in these areas. AHP method had more accurate indicators than Boolean methods.

In the first part, nine categories of variables were specified as the factors affecting the location of medical centers through the conducted studies. These variables were completed using AHP questionnaire by seven relevant experts indicating that the access to main roads in district 1 of Tehran had a high significance. Then, other indicators such as urban uses and their distance to medical centers were placed at the second level. 


\section{REFERENCES}

1. Farah Abadi, Seyyed Mohammad Ehsan; Yousefi, Mehdi; Ziari, Bahman; Fereidouni, Najmeh; Fazaeli, Fatemeh (2010). Efficiency analysis of selected urban medical centers affiliated to Isfahan University of Medical Sciences. Journal of Hospital. 2

2. United Nations 2004 World Urbanization Prospects, The 2003 Revision UNITED NATIONS PUBLICATION. New York Department of Economic \& Social Affairs

3. Sarvar, Rahim; Moosavi, Mirnajaf; Yazdani, Rasul. (2013). Spatial distribution and medical services location analysis using fuzzy multicriteria decision making model. Quarterly Journal of Environment, 82-102

4. Purmohammadi, M. (2003). Urban land use planning. Tehran: Samt.

5. Sharifzadegan, M; Mammadvahi, A; Lavi, M. (2010). Space inequality in access to public health services for urban health development by the p-median model in Isfahan. Social welfare quarterly. 265-285.

6. Williams, Jonathon. (1997). Geographical information of space. Tehran: GIS in Tehran

7. Yekanifard, Ahmadreza. (2001). The principles of locating medical centers. Quarterly Journal of Municipalities, Third Year, No. 23, 83-104

8. Azizi, Mansur. (2004). GIS application in location, spatial distribution and analysis

9. Network health centers, Case study: Mahabad. Tabriz University, master's thesis.

10. Hafeznia, Muhammadreza. (2010). An Introduction to the research method in humanities. Tehran: Samt.

11. Hopkins, L.D. (1977). Methods for generating land suitability maps: A comparative evaluation. Journal for American Institute of Planners, 1929.

12. Ravalli. (2008). The Land Suitability Analysis. County Planning Department.

13. 2002 Urban Land Use Planning. Tehran30

14. Shi-e, 1992 Introduction to Urban Planning96

15. Rahmanpour 2009 Locate the schools and the Journal of Geography Education24
16. Litkuhi, Sanaz; Jahanbakhs, Heydar; Charkhchiyan, Maryam. (2014). Theory of location. Tehran: arts and architecture: Payame Noor University.

17. Shie, Esmail. (1991). Environmental talents, the basis for the physical design of Iranian biotechnology complexes. International Conference on National and Regional Physical Design, Ministry of Housing and Urban Development. Isfahan.

18. Ziari, keramatollah. (2002). Urban land use planning. Yazd: Yazd University Press.

19. Shie, Esmail. (1992). An introduction to the basics of urban planning. Tehran: Iran University of Science and Technology.

20. Bahreyini, Seyyed Hussein. (2007). Urban design process. Tehran: Tehran University.

21. Schmid, V \&, .Doerner, K. (2012). Ambulance location and relocation problems with timedependent travel times.

22. Ghasban, Fereydoon. (1996). Environmental geology (Volume 1). Tehran University Press.

23. Sanayi Nejad, Seyyed Fereydoon; Faraji, Hasan Ali. (1999). GIS application using ARC / INFO in urban and regional planning. Jahad Daneshgahi of Mashhad

24. Bazazi, Muhammad. https://modirsun.com/Page/Detail/111

25. Sanayi Nejad, Seyyed Fereydoon; Faraji, Hasan Ali. (1999). GIS application using ARC / INFO in urban and regional planning. Jahad Daneshgahi of Mashhad. 